\title{
BUCCAL FAT PAD REINFORCE BUCCAL ADVANCEMENT FLAP VS ROTATIONAL PALATAL FLAP IN CHRONIC OROANTRAL FISTULA TREATMENT
}

\author{
Mohamed Mostafa Elshamaa *, Samir Ali Elborolosy* \\ and Hamada Abdel Hie Hamid Mahran**
}

\begin{abstract}
Background: Oroantral Fistula (OAF), the most common complication after extraction of posterior maxillary teeth leading to chronic maxillary sinusitis, patient discomfort and can cause difficulty in speech, mastication, and overall hygiene of the patient. Many treatment approaches have been developed to treat OAFs; Buccal Fat Pad (BFP) as a graft material, Buccal Advancement flap (BAF) and rotational palatal flap (RPF).
\end{abstract}

Aim: To compare two treatment modalities for the management of Oroantral Fistula (OAF). We compared the clinical outcomes for both Buccal Fat Pad (BFP) reinforce Buccal Advancement flap (BAF) and rotational palatal flap(RPF) treatment approaches.

Material and Methods: A total of 76 patients were included in this randomized controlled clinical study and were divided into two groups; Group A: treated with BFP reinforce BAF, and Group B: treated with RPF. Both procedures were performed under local anesthesia. All the patients were assessed clinically by Valsalva test at 1 week and 4 weeks post-surgical where the surgical sites were examined by direct visual examination for the amount of both epithelization and closure of the OAF.

Results: Our results showed no statistical significant difference $(\mathrm{P}>0.05)$ in the clinical outcomes of for both tested OAF treatments

Conclusion: Both treatment approaches are good and dependable in the management of OAF.

KEY WORDS: Buccal advancement flap, Oroantral Fistula, Palatal rotation flap, Buccal Fat Pad.

\footnotetext{
* Lecturer, Oral and Maxillofacial Surgery Department Faculty of Dentistry. Beni-Suef University, Egypt.

** Lecturer of Maxillofacial Surgery, General Surgery Department, Faculty of Medicine, Assiut University, Egypt.
} 


\section{INTRODUCTION}

An abnormal pathway between the oral cavity and the maxillary sinus is known as Oroantral Fistula (OAF). The most common cause of OAF is traumatic extraction of maxillary premolars and molars in more than $48 \%$ of the cases, where roots projection into the sinus is the main reason why this communication to occur. ${ }^{1}$

It was measured that the bone between the root apices of the maxillary posterior teeth and the maxillary sinus around $0.5 \mathrm{~mm} .^{2}$ It was also presented that the most frequently associated teeth with OAF are the second molars with an incidence of $45 \%$, followed by the third molars with an incidence of $30 \%$ and first molars with $27.2 \%$. The least presented teeth were found to be the first premolars with an incidence of 5.3\%. Other causes of oroantral communication include trauma, cyst, implant dislodgement, fracture tuberosity, osteoradionecrosis, tumors in the maxillary sinus, dehiscence after implant, flap necrosis, and periapical infection. ${ }^{3,4}$

Urgent closure of oroantral communication is essential to avoid accumulation of saliva orfood which causes sinus contamination and leads to impaired healing, infection and chronic sinusitis. ${ }^{5}$ Undiagnosed or untreated large communications rarely heal and will consequently result in OAF. When formed, OAF results in maxillary sinusitis, epithelialization of the fistula tract, dental apical abscess, osteitis or osteomyelitis on the communication's margins dental cysts, foreign bodies, or tumors, where all will prevent spontaneous healing causing the formation of chronic fistula. Thus, maxillary sinus pathology elimination is obligatory for successfulOAFtreatment. ${ }^{6}$

Many studies have presented different techniques for OAF closure these includes; simple primary closure, BAF, PRF, bone grafts, allogenic graft, regional flap, split-thickness skin graft, distant flaps, or BFP?
In 1930 Axhausen first introduced the buccal flap as a treatment approach for OAF.He modified the vestibular flap technique, where he used a flap dissected from bucally placed vertical incisions together with a thin layer of buccinator muscle to close OAF. He suggested using this technique in cases with severe alveolar bone resorption. The main disadvantage of this technique was the loss of vestibular sulcus. ${ }^{8}$

Another described treatment approach was the palatal flap which is performed by incising the palatal mucosa, with preservation of its posterior base for flap blood supply, where the flap is then rotated laterally and passed under the gingival margin to be closely adapted at the recipient surgical site. In some studies, a mucosal flap is described to cover the exposed palatal bone to reduction donor site morbidity. ${ }^{9}$

In search of other techniques for OAF closure, the BFP was introduced, in which a pedicled graft of lobulated fatty tissue enclosed by a thin fibrous capsule is dissected from the cheek mucosa. ${ }^{10-12,13} \mathrm{An}$ alternative procedure commonly used for the closure of the OAF is the PRF. A palatal flap anteriorly or posteriorly based contains a large palatine vessel to ensure adequate blood flow. It is suggested that this technique has a success rate of $76 \%$. It is less vulnerable to rupture than the buccal flap because of the thickness of the palatal mucosa. Furthermore, the buccal sulcus depth remains intact. The disadvantage of the palatal flap is the soft tissue bulge at the axis of rotation and the denuded palatal donor area, which causes greater discomfort for the patient compared with other soft tissue techniques. ${ }^{14}$ Some studies considered BAF with or without a buccal pad of fat as the ideal method for OAF treatment, while others strongly adopted the use of palatal rotational flap although there are no comparative studies are available up till now. This study aims to compare the clinical outcome of two main treatment techniques for OAF; BFP reinforce BAF and PRF. 


\section{MATERIALS AND METHODS}

This Randomized controlled clinical trial was performed in the outpatient clinics Faculty of dentistry, Beni-Suef University and to confirm that the study meets national and international guidelines for research on humans, ethical approval for all performed protocols was approved by the Faculty of dentistry Beni-Suef University Research Ethics Committee (FDBSUREC) under the IORG \#: IORG0010018. A signed informative consent was obtained from all included patients and expected outcomes were clearly presented and discussed.

A total of seventy-six patients were included in this study. They were divided into two groups; Group A: Thirty-eight patients were treated with BFP reinforce BAF, and Group B: Thirty-eight patients were treated with RPF.

Inclusion criteria included: Long-standing fistula, failure of primary closure, defect greater than $6 \mathrm{~mm}$, positive nose blow test and history of a tooth extraction with irrespective of age and gender. Exclusion criteria included: Medically compromised patients, smoking habits, pre-existing sinus pathologies, foreign bodies in the area of fistula, previous sinus surgery and patients with a sinus infection.

\section{Data Collection}

Patient's demographic data like patient's name, age, and gender were carefully recorded. Routine investigations and cone-beam computed tomography (CBCT) were obtained. Any pre-existing sinusitis was treated with nasal decongestant and antibiotics.

Patients were selected randomly via the lottery method and were then divided into two groups. Group A; treated with BFP reinforce BAF and Group B; treated with RPF.

Before surgery the mucosa was carefully debrided up to the well-perfused tissue and the infected bony structures was thoroughly curetted.
All surgical procedures were performed under local anesthesia (Alexadricaine 1:100000.Alexandria Co. for Pharmaceutical \& Chemical Industries) by the same surgeon for standardization purpose and to limit biasness. All patients were assessed clinically using the nose blow test at 1 and 4weekspostsurgical for the assessment of surgical outcomes. Positive nose blow test indicated the failure of the flap treatment. A negative nose blow test was considered a success of the treatment. The test involves pinching the nostrils together to occlude the patient's nose and asking the patient to blow gently through the nose while the surgeon observed the flap area. If there was no passage of air or bubbling of blood immediately after flap closure, then the test was considered as a negative nose blow test and flap was then assessed clinically for the epithelization. In case of negative nose blow test with complete epithelization and lack of any continuity defects the flap was considered successful.

\section{Surgical Technique}

For group A (Fig. 1A, B) surgical procedure was performed as follows; After fistulectomy, two divergent mucoperiosteal incisions $1 \mathrm{~cm}$ from the anterior and posterior edges of the bony defect were made and extended to the height of the mucobuccal fold. Full-thickness buccal mucoperiosteal flap was reflected and horizontal scoring of the periosteum was performed to allow advancement of a tensionfree flap over to the palatal side. After the anterior side of the flap was extended forward, the BFP was exposed till adequate bulk of fat was mobilized at the surgical site. The harvested fat was sutured to the palatal mucosa using 3.0 vicryl sutures (VISORB 3/0 Polyglycolic Acid) and the closure was provided over the bone with mattress suture from the buccal flap to palatal mucosa in two layers using BFP and BAF.

For Group B (Fig. 1A, B) after fistulectomy by circular excision around the orifice of the fistula was made using No. 11 bard parker blade. 
A full-thickness incision was made lateral to the vascular supply and extended 2-3 $\mathrm{mm}$ short of the palatal side of the teeth. The incision was extended up to the palatal mucosa of the lateral incisor. A full-thickness mucoperiosteal flap was raised from anterior to posterior; care was taken as the vascular supply was approached. Once the flap was elevated, the modified palatal flap rotated lifting an adequate tissue bridge for the placement of the flap underneath this tissue bridge and sutured on the donor site without any tension.

\section{Follow-up}

Immediate postoperative instructions were given. Patients were directed to only use soft diet and not to oral rinses vigorously or sneeze with a closed mouth or to nose blow. For all patients, nasal decongestant
(Otrivin 0.1\% Nasal Spray $10 \mathrm{ml}$. Novartis Co.) and a broad spectrum antibiotic (Augmentin $1 \mathrm{gm}$. GlaxoSmithKline Co.) was prescribed for a week. All patients were clinically re-evaluated weekly post-postoperatively to identify and manage any complication.

\section{Statistical analysis of the data}

Data were fed to the computer and analyzed using IBM SPSS software package version 20.0. (Armonk, NY: IBM Corp). Quantitative data were described using range (minimum and maximum), mean, standard deviation, and median. Student t-test was assessed for normally distributed quantitative variables, to compare between two studied groups. The significance of the obtained results was judged at the $5 \%$ level.

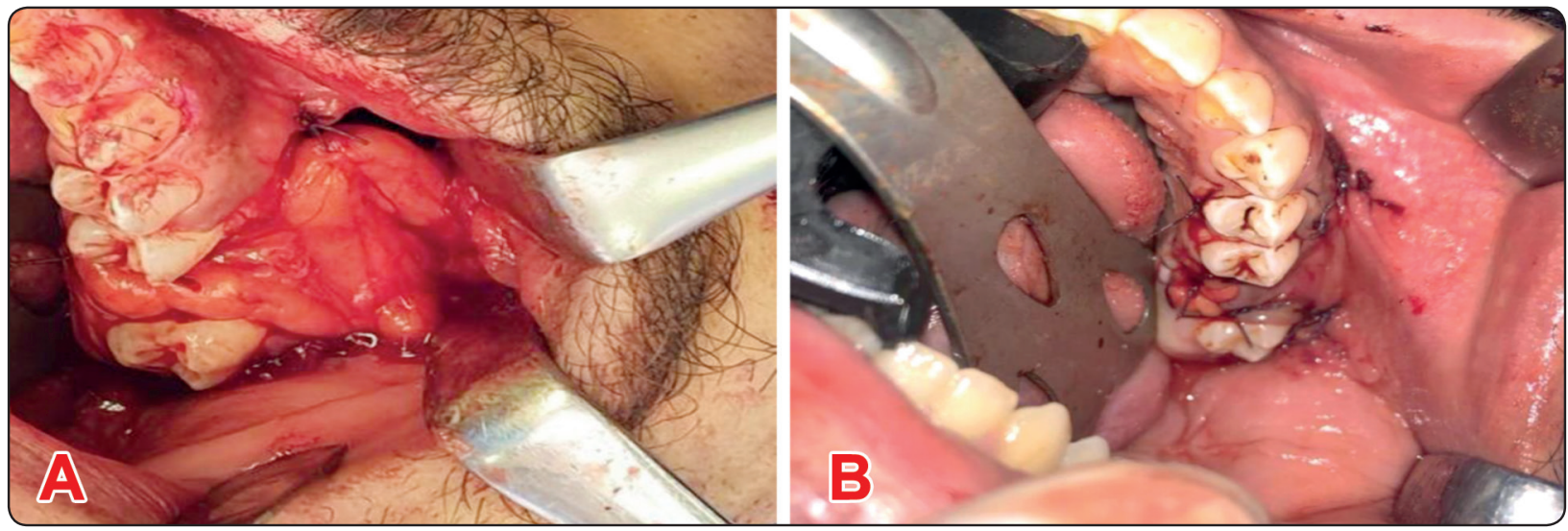

Fig. (1) A. Buccal fat pad (BFP) sutured in place. B. Closure of oroantral fistula with Buccal Advancement Flap
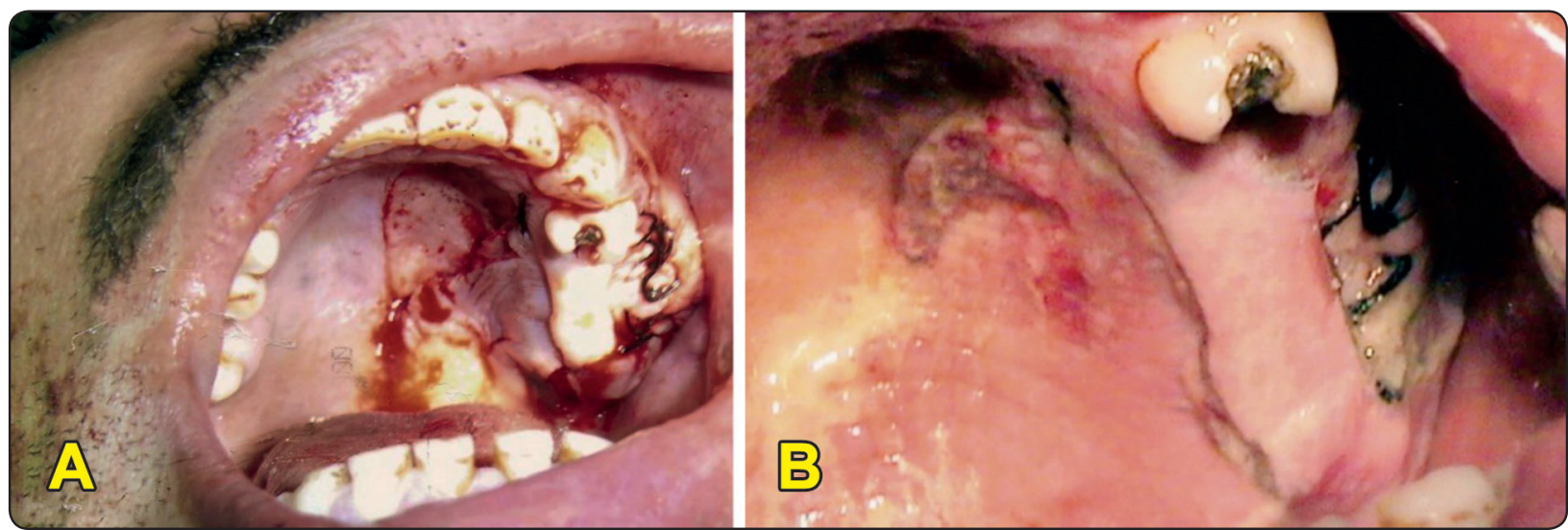

Fig. (2) A. Closure of oroantral fistula with palatal flap. B. 2 weeks follow-up shows formation of secondary epithelialization of the raw area. 


\section{RESULTS}

The mean age was $33.08 \pm 6.87$ years in group $\mathrm{A}$ and $34.29 \pm 6.07$ years was in group B. The mean age for both groups was $33.68 \pm 6.47$, with no statistical difference between the two groups. The age group distribution in group A was 19 cases ranging between $31-40$ years $(50 \%)$ followed by 15 cases ranging between $20-30$ years $(39.5 \%)$. In group B 24 cases ranged between $31-40$ years $(63 \%)$ and 11 case ranged between 21-30 years (29\%). Our results showed that there was a significant difference in OAF occurrence between males and females, where the mean was found to be1.7:1 in favor of males. Group A included 23 males (60.5\%) and 15 females (39.5\%), while Group B included 25 males $(66 \%)$ and 13 females $(34 \%)$ (Tables1, 2).

TABLE (1): Frequency of age groups and gender in both groups of flap $(n=76)$

\begin{tabular}{|c|c|c|}
\hline Variable & Group A & Group B \\
\hline \multicolumn{3}{|l|}{ Age (years) } \\
\hline $20-30$ & $15(39.5 \%)$ & $11(29 \%)$ \\
\hline $31-40$ & $19(50 \%)$ & $24(63 \%)$ \\
\hline $41-50$ & $4(10.5 \%)$ & $3(8 \%)$ \\
\hline \multicolumn{3}{|l|}{ Gender } \\
\hline Male & $23(60.5 \%)$ & $25(66 \%)$ \\
\hline Female & $15(39.5 \%)$ & $13(34 \%)$ \\
\hline
\end{tabular}

TABLE (2): Comparison between the two studied group according to age and size of defect (mm)

\begin{tabular}{|c|c|c|c|c|}
\hline & $\begin{array}{c}\text { Group A } \\
(\mathbf{n}=\mathbf{3 8})\end{array}$ & $\begin{array}{c}\text { Group B } \\
(\mathbf{n}=\mathbf{3 8})\end{array}$ & $\mathbf{t}$ & $\mathbf{p}$ \\
\hline \multicolumn{5}{|l|}{ Age (years) } \\
\hline $\begin{array}{l}\text { Median } \\
\text { (Min - Max) }\end{array}$ & $\begin{array}{c}32 \\
(22.0-50.0)\end{array}$ & $\begin{array}{c}36.50 \\
(22.0-48.0)\end{array}$ & \multirow{2}{*}{0.814} & \multirow{2}{*}{0.418} \\
\hline Mean \pm SD & $33.08 \pm 6.87$ & $34.29 \pm 6.07$ & & \\
\hline \multicolumn{5}{|c|}{ Size of defect (mm) } \\
\hline $\begin{array}{l}\text { Median } \\
\text { (Min - Max) }\end{array}$ & $\begin{array}{c}8.0 \\
(7.0-15.0)\end{array}$ & $\begin{array}{c}8.0 \\
(7.0-13.0)\end{array}$ & \multirow{2}{*}{0.199} & \multirow[t]{2}{*}{0.843} \\
\hline Mean \pm SD & $8.50 \pm 1.9$ & $8.42 \pm 1.54$ & & \\
\hline
\end{tabular}

$t$ :Student $t$-test $\quad p: p$ value for comparing between the two studied groups
The mean defect size in group A and B were 8.50 $\pm 1.9 \mathrm{~mm}$ and $8.42 \pm 1.54 \mathrm{~mm}$ respectively with no statistical difference between the two groups. For Group A, the defect size distribution was $84 \%$ in the range of6-10 $\mathrm{mm}$ followed by $16 \%$ in the range of 10-15 mm. Similarly, in Group B92\% were in the range of6-10 $\mathrm{mm}$ followed by $8 \%$ in the range of 10 $15 \mathrm{~mm}$ (Table 3).

TABLE (3): Frequency and percentage of region, cause and size of OAC in both groups $(n=76)$

\begin{tabular}{|l|c|c|}
\hline Variable & Group A(n =38) & Group B(n=38) \\
\hline Region of OAC \\
\hline Molar region & $29(76 \%)$ & $31(81.5 \%)$ \\
\hline Premolar region & $9(24 \%)$ & $7(18.5 \%)$ \\
\hline Causes of OAC \\
\hline Tooth extraction & $37(97 \%)$ & $37(97 \%)$ \\
\hline Trauma & $1(3 \%)$ & 0 \\
\hline cyst & 0 & $1(3 \%)$ \\
\hline Size of defect(mm) & $32(84 \%)$ & $35(92 \%)$ \\
\hline $6-10$ & $6(16 \%)$ & $3(8 \%)$ \\
\hline $10-15$ &
\end{tabular}

Traumatic dental extraction was the most reason for the OAF in $97 \%$ of the patients included in this study in both groups. Of these $97 \%$, upper molar extractions comprised $76 \%$ of Group A and $81.5 \%$ of Group B cases.

No statistical significance was found regarding the success rate (97\%) between both flap groups $(\mathrm{P}=1.000)$ and $1(3 \%)$ female patient has no success in group $\mathrm{A}$, she had complete wound dehiscence and recurrent fistula due to old massive facial trauma, her buccal pad of fat was atrophied with extensive cheek scaring, while in group B, only one male patient his palatal flap is not suitable for closure of OAF because it was related to maxillary tuberosity; in which turning the flap over this lead to its folding and therefore jeopardize the blood supply (Table 4). One major expected complaint for 
Group A patients was the sense of loss of sulcular depth by the tongue. Also, all Group B patients suffered of temporary discomfort due to exposed palatal bone after elevation of the rotational palatal flap, yet this disappeared immediately after healing with secondary epithelialization within 2 weeks. (Fig.2.B)

TABLE (4): Frequency and percentage of success and failure rate in both groups $(n=76)$

\begin{tabular}{|c|c|c|l|}
\cline { 1 - 3 } Variable & $\begin{array}{c}\text { Group A } \\
(\mathbf{n = 3 8})\end{array}$ & $\begin{array}{c}\text { Group B } \\
(\mathbf{n = 3 8})\end{array}$ & \multirow{2}{*}{ P value } \\
\cline { 1 - 3 } Success & $37(97 \%)$ & $37(97 \%)$ & \multirow{2}{*}{1.000} \\
\cline { 1 - 3 } Failure & $1(3 \%)$ & $1(3 \%)$ & \\
\hline
\end{tabular}

\section{DISCUSSION}

The major objective of OAF management is the complete closure of the defect and the prevention of food debris and oral bacteria from penetrating to the sinus. OAF can cause sinus contamination leading to infection, impeded healing, and chronic sinusitis. Fistulae larger than $5 \mathrm{~mm}$ in diameter or those that persist for more than 3 weeks rarely heal spontaneously and will typically require surgical intervention. ${ }^{15}$

For a successful OAF treatment, it is crucial to always operate in a disease-free sinus environment, thus mucosa should be debrided up to the wellperfused tissue and the infected bony structures should be curetted. In addition, adequate vascularization of the flap, sufficient flap width and length with minimum tension are important factors for the success of the flap treatment of OAF. ${ }^{16,17}$

The most common cause for the development of $\mathrm{OAF}$ is tooth extraction. It was suggested that extraction of the maxillary posterior teeth is the most common etiologic factor for oroantral communications. ${ }^{1}$ Similarly, $97 \%$ of the cases included in our study was due to traumatic dental extraction, and mainly due to upper molar extraction.
In our study, only two cases developed OAF for reasons other than extractions. One case developed OAF due to excision of a maxillary cyst, while the other case was due to facial trauma.

In the present study, OAF was found to be significantly more common in males than females. This was also reported in many other studies, sexual dimorphism in OAF, with males showing more frequency than females, this difference can be explained by a higher overall frequency of traumatic tooth extraction in men..$^{8,17-21}$

The most range of size of defect was $6-10 \mathrm{~mm}$ $32(84 \%)$ followed by $10-15 \mathrm{~mm} 6(16 \%)$ in group A. Similarly the most range of size of defect was 6-10 mm 35 (92\%) followed by $10-15 \mathrm{~mm} 3(8 \%)$ in group B. In OAF, $5.4 \mathrm{~mm}$ size defect was reported average width diameter in other studies. ${ }^{1}$

In our study generally the mean age for the patients in group A was $33.08 \pm 6.87$ and $34.29 \pm 6.07$ years was in group B. Overall mean age was $33.68 \pm$ 6.47 years. Most of the patients were in 3rd and 4th decades in both groups which is in agreement with other studies ${ }^{18,19}$ whom reported that the mean age of $34.03 \pm 10.56$ years.

Several techniques have been described for OAF closure. Successful results were obtained by using buccal flap and palatal rotational flap. Buccal flap technique has the advantage of closeness of the harvesting area to the defect site which makes it a favored procedure to many clinicians for the closure of small to moderate size fistulae. ${ }^{22,23}$ Despite the easier surgical procedure of buccal advancement flap, perfusion of buccal flaps are poor and narrowing of the gingivobuccal sulcus may occur. ${ }^{24}$ It has been shown that failure possibility is present and patients should be informed about the need for another trial for closure of the OAF. ${ }^{25-27}$

$\mathrm{BAF}$ reinforced by BFP is described as an easier modified surgical procedure of the buccal 
flap technique to collect the advantages of BFP and BAF. Advantages of using BFP as a graft material include the great ability of utilization, in significant donor site morbidity and nourishing blood supply from the buccal and deep temporal branches of the maxillary artery, the transverse branch of the superficial temporal artery and branches of the facial artery makes the uncovered fat to epithelize by itself within two to three weeks after the surgery. ${ }^{24-26}$ Using only BFP has some drawbacks including graft necrosis and new fistula formation when it is used for closure of large defects. ${ }^{24}$ Also it is contraindicated to use BFP reinforced buccal flap in patients with previous history of radiotherapy which result in rigidity, stiffness and diminished size of the fat pad in addition to reduced vascularity resulting in poor prognosis of the surgery. ${ }^{27-30}$

In our study we could confirm that BFP reinforced BAF was easy and relatively safe with minor complications, unlike some literature which reported hematoma, flap necrosis, scarring, infection and facial nerve damage as possible complications ${ }^{31}$ In this study none of these complications were seen.

Palatal rotational flap technique was suggested by many authors to be the treatment of choice in treating large OAF as good flap vascularity is secured from the greater palatine artery, thus facilitating the repair of these challenging defects. One more advantage of this technique is the plentiful amount of keratinized mucosa that can aid in the outcome of the planned future implant placement by enhancing the gingival biotype in that area. ${ }^{32,33}$

We suggest that the failure of one case of Group B treated with rotational palatal flap technique was due to over rotation of the flap, owing to the extremely posterior position of the OAF which was related to the position of the upper third molar near the tuberosity, which possibly reduced the blood supply to the flap leading to its stiffness and failure of defect closure. In palatal rotational flap technique donor site necrosis is a very rare complication, yet only one study reported a case of 43-year-old female with Type I diabetes presented with a chronic oroantral fistula in the right second molar region where bony necrosis was described in the donor site following palatal rotational flap operation. ${ }^{31}$ In our study we excluded all medically compromised patients to avoid this type of complication. We suggest that using palatal flap technique for closure of OAF will avoid the loss of vestibule depth which is a common disadvantage of other techniques including the buccal flap.

We found no significant difference when we compared the two surgical techniques which is consistent with many other studies. ${ }^{18,34}$ We suggest that surgeon preference and experience are the main factors for preferring any of the tested surgical techniques. It is worth saying that we suggest that the palatal flap technique is contraindicated in case of extremely posteriorly located OAF mainly those related to the tuberosity due to risk of over twisting of the flap which jeopardize its blood supply and may lead to failure of defect closure.

BFP reinforce BAF technique in many cases we could not find sufficient buccal fat pad to use for adequate closure of the OAF so we should seek for an alternative surgical technique. Also, we suggested that the failure of one case in group A, she had complete wound dehiscence and recurrent fistula because her buccal pad of fat was atrophied with extensive cheek scaring due to old massive facial trauma, while in group $\mathrm{B}$, only one male patient his palatal flap is not suitable for closure of OAF because it was related to maxillary tuberosity; in which turning the flap over this lead to its folding and therefore jeopardize the blood supply. Due to the limited sample size in our study we recommend future studies with larger sample size and more surgical techniques comparisons. 


\section{REFERENCES}

1. Hassan O, Shoukry T, Raouf AA, Wahba H. Combined palatal and buccal flaps in oroantral fistula repair. Egyptian Journal of ENT and Allied Sciences 2012;13:77-81.

2. Harrison DF. Oro-antral fistula. Br J ClinPract. 1961; 15:169-74.

3. Scattarella A, Ballini A, Grassi FR, Carbonara A, Ciccolella F, Dituri A, Nardi GM, Cantore S, Pettini F. Treatment of oroantral fistula with autologous bone graft and application of a non-reabsorbable membrane. Int J Med Sci 2010;7:267-71.

4. Khandelwal P, Hajira N. Management of Oro-antral Communication and Fistula: Various Surgical Options. World J PlastSurg 2017;6:3-8.

5. Borgonovo AE, Berardinelli FV, Favale M, Maiorana C. Surgical options in oroantral fistula treatment. Open Dent J 2012;6:94-8.

6. Yalçın S, Oncü B, Emes Y, Atalay B, Aktaş I. Surgical treatment of oroantral fistulas: a clinical study of 23 cases. J Oral Maxillofac Surg. 2011;69:333-9.

7. Visscher SH, van Minnen B, Bos RR. Closure of oroantralcommunications: A review of literature. J Oral Maxillofac Surg. 2010;68:1384-91.

8. Killey HC, Kay LW. An analysis of 250 cases of oro- antral fistula treated by the buccal flap operation. Oral Surg Oral Med Oral Pathol. 1967;24:726-39.

9. Yamazaki Y, Yamaoka M, Hirayama M, Shimada H. The submucosal island flap in the closure of oro-antral fistula. Br J Oral Maxillofac Surg. 1985;23:259-63.

10. Martín-Granizo R, Naval L, Costas A, Goizueta C, Rodriguez F, Monje F, et al. Use of buccal fat pad to repair intraoral defects: re- view of 30 cases. Br J Oral MaxillofacSurg 1997;35:81-4.

11. el-Hakim IE, el-Fakharany AM. The use of the pedicledbuccal fat pad (BFP) and palatal rotating flaps in closure of oroantral communication and palatal defects. J LaryngolOtol 1999;113:834-8

12. Rapidis AD, Alexandridis CA, Eleftheriadis E, Angelopoulos AP. The use of the buccal fat pad for reconstruction of oral defects: re- view of the literature and report of 15 cases. J Oral MaxillofacSurg 2000;58:158-63.

13. Egyedi P. Utilization of the buccal fat pad for closure of oro-antral and/or oro-nasal communications. J Maxillofac Surg 1997;5:241-4.
14. Renton T, Durham J, Hill CM. Oral surgery II: Part 2. The maxillary sinus (antrum) and oral surgery. British dent J. 2017;22:483-93.

15. Kraut RA, Smith RV. Team approach for closure of oroantral and oronasal fistulae. Atlas Oral Maxillofac Surg Clin North Am. 2000;8:55-75.

16. Gendy S. Etiology and Management of Oro- Antral Fistula. Annals of Otolaryngology and Rhinology. 2016;3:1122

17. Yilmaz T, Suslu AE, Gursel B. Treatment of oroantralfistula: experience with 27 cases. Am J Otolaryngol. 2003; 24:221-3.

18. Qureshi ZR, Khan M, Qiam ud Din, Buccal advancement flap vs palatal rotation flap in the management of oroantral fistula. JKCD 2012;2:54 - 7 .

19. Güven O. A clinical study on oroantral fistulae. J Craniomaxillofac Surg.1998; 26:267-71.

20. Elarbi MS. The management of an oroantral fistula: a clinical study of 30 cases. Pak Oral Dent J. 2006;26:55-58.

21. Galíndez BD, Sánchez ÓJG, Carreón MV, Zúñiga DA. Surgical correction of oroantral fistulas with integration of mandibular bone. Revista Médica del Instituto Mexicano del Seguro Social 2005; 43:167-72.

22. Awang MN. Closure of oroantral fistula. Int J Oral Maxillofac Surg. 1988; 17:110-5.

23. Er N, Tuncer HY, Karaca C, Copuroğlu S. Treatment of oroantral fistulas using bony press-fit technique. J Oral Maxillofac Surg. 2013;71:659-66.

24. Stajcić Z. The buccal fat pad in the closure of oro-antral communications: a study of 56 cases. J Craniomaxillofac Surg. 1992;20:193-7.

25. Baumann A, Ewers R. Application of the buccal fat pad in oral reconstruction. J Oral Maxillofac Surg. 2000;58:389-92.

26. Yang S, Jee YJ, Ryu DM. Reconstruction of large oroantral defects using a pedicledbuccal fat pad. Maxillofac Plast Reconstr Surg. 2018;40:7.

27. Parvini P, Obreja K, Begic A, Schwarz F, Becker J, Sader $\mathrm{R}$, et al. Decision-making in closure of oroantral communication and fis- tula. Int J Implant Dent. 2019;5:13.

28. Paterson C, Thomson MC, Caldwell B, Young R, McLean A, Por- teous S, et al. Radiotherapy-induced xerostomia: a randomised, double-blind, controlled trial of Visco-easeTM oral spray compared with placebo in patients with cancer of the head and neck. Br J Oral Maxillofac Surg. 2019;57:1119-25. 
29. Dirix P, Nuyts S, Van den Bogaert W. Radiation-induced xerostomia in patients with head and neck cancer: a literature review. Cancer. 2006;107:2525-34.

30. Vissink A, Mitchell JB, Baum BJ, Limesand KH, Jensen SB, Fox PC, et al. Clinical management of salivary gland hypofunction and xerostomia in head-and-neck cancer patients: successes and barri- ers. Int J Radiat Oncol Biol Phys. 2010;78:983-91.

31. Erdoğan Ö, Esen E, Üstün Y. Bony palatal necrosis in a diabetic patient secondary to palatal rotational flap. J Diabetes Complications. 2005; 19:364-7.
32. Lin GH, Chan HL, Wang HL. The significance of keratinized mucosa on implant health: a systematic review. J Periodontol. 2013;84:1755-67.

33. Brito C, Tenenbaum HC, Wong BK, Schmitt C, NogueiraFilhoG. Is keratinized mucosa indispensable to maintain peri-implant health? A systematic review of the literature. J Biomed Mater Res B Appl Biomater. 2014;102:643-50.

34. Anavi Y, Gal G, Silfen R, Calderon S. Palatal rotationadvancement flap for delayed repair of oroantral fistula: a retrospective evaluation of 63 cases. Oral Surg Oral Med Oral Pathol Oral Radiol Endod 2003;96:527-34. 